\title{
Light-Emitting Diodes (LEDs) for Miniature Hydroponic Lettuce
}

\author{
Kent Kobayashi, Teresita Amore, Michelle Lazaro \\ Tropical Plant \& Soil Sciences Department, University of Hawaii at Manoa, Honolulu, USA \\ Email: kentko@hawaii.edu
}

Received December 11, 2012; revised January 12, 2013; accepted January 19, 2013

\begin{abstract}
There is growing concern about food safety, environmental impact, and efficient energy usage in agricultural production systems. Producing lettuce under artificial lighting could be a solution addressing these concerns. Light-emitting diodes (LEDs) offer the advantages of a narrow light spectrum, low power consumption, and little heat production. The objective of this study was to determine the effects of different light sources on the growth of miniature "Tom Thumb" butterhead lettuce in a non-circulating hydroponic system. Lettuce seedlings, started in Oasis Horticubes, were transferred to net pots in containers with a hydroponic nutrient solution. The lettuce was grown in a lab under three light treatments - blue LEDs, red LEDs, and fluorescent lights. At the end of the study, fluorescent lights resulted in greater root dry weight than blue LEDs and red LEDs. Total plant dry weight under fluorescent lights was greater than under red LEDs. There were no significant differences in shoot dry weight and plant height among the treatments. Percent partitioning of dry weight to shoots was greatest with red LEDs, followed by blue LEDS, and fluorescent lights. Percent partitioning of dry weight to roots was greatest with fluorescent lights, followed by blue LEDS, and red LEDs. Leaf chlorophyll content was greater under blue LEDs and fluorescent lights than red LEDs. The $\mathrm{pH}$ of the nutrient solution of the blue LED and the fluorescent light treatments were greater than the red LED treatment. Electrical conductivity of the nutrient solution of the fluorescent light treatment was greater than the blue LED treatment and the red LED treatment. In conclusion, LEDs could provide an alternative lighting source for miniature lettuce production.
\end{abstract}

Keywords: Non-Circulating Hydroponics; Vegetable Production; Artificial Lighting; Lactuca Sativa

\section{Introduction}

There is growing concern about efficient energy usage, environmental impact, and food safety in agricultural production systems [1]. In reducing energy usage for crop production, LEDs are efficient form of lighting because it uses low energy consumption. Its low heat production means less energy is used for cooling growing structures such as glasshouses, greenhouses, and plant factories [2,3]. Providing the crop with the specific wavelengths of light it requires translates to less energy being used for growing the crop.

Hydroponics uses a soilless system for growing crops. Typically, a nutrient solution is applied to the crop in various ways. In non-circulating hydroponics, the crop is supported on a styrofoam board floating on a nutrient solution [4]. Other hydroponic systems include nutrient film technique, ebb and flow, and aeroponics. Growing vegetables hydroponically enables better control of the environment including weather factors, pests and diseases, and plant nutrient management. Because a specially formulated nutrient solution is used in hydroponics, no excess fertilizer is wasted and leaching of fertilizers into the ground or the groundwater system is reduced. There is less environmental impact due to reduced leaching and less pests and diseases. The concern of food safety is addressed through better control of the environment and microclimate around the crop so as not to introduce unwanted pests, pesticides, and microorganisms.

Producing vegetables such as lettuce under artificial lighting could help address the above concerns. Highintensity discharge lighting such as high pressure sodium [5] and metal halide have been used but give off too much heat and increase the temperature of the leaves. Light-emitting diodes (LEDs) offer the advantages of a narrow light spectrum, low power consumption, and little heat production $[2,3,6-9]$. The specific light wavelengths for photosynthesis and other crop physiological processes can be controlled by the grower.

With the advent of LEDs, increasing research and commercial production involving the use of LEDs has occurred. Studies have looked at different color LEDs, different color fluorescent lights, and various combinations of these two on crop production. High power LED 
lighting systems have been shown to accelerate the growth rate of lettuce compared to plants grown under normal solar irradiance [10]. Johkan [11] found that in red leaf lettuce, red LEDs increased leaf area 33\% compared to fluorescent light.

There is a lack of information on the use of LEDs for hydroponically grown miniature vegetables. Our study looked at miniature vegetables because they offer high production in a limited space. Plants can be placed close to each other (high density planting) and their height allows shelving that support the plants to be placed closer together vertically. The objective of this study was to determine the effects of different light sources on the growth of "Tom Thumb" miniature butterhead lettuce in a non-circulating hydroponic system.

\section{Materials and Methods}

Two "Tom Thumb" lettuce seeds (Territorial Seed Co., Cottage Grove, OR) were placed in each hole of $2.5 \mathrm{~cm} \times$ $3.8 \mathrm{~cm}$ Oasis ${ }^{\circledR}$ Horticubes (Oasis Grower Solutions, Kent, $\mathrm{OH})$. The Horticubes were moistened with tap water and placed in plastic trays with clear covers. The trays were put on a laboratory bench under ambient light conditions and room temperature.

When the seedlings had one set of fully expanded leaves, they were thinned to one seedling per Horticube. The Horticubes were transferred to $5.1 \mathrm{~cm}$ diameter plastic net pots and placed in 1.9-liter containers containing a hydroponic nutrient solution. The solution was HydroGardens' Chem-Grow Lettuce Formula 8-15-36 (N-P-K) hydroponic fertilizer with calcium nitrate (15.5\%-0-0) and magnesium sulfate $(9.8 \% \mathrm{Mg}$ ) (Hydro-Gardens, Colorado Springs, CO). The nutrient solution contained $0.60 \mathrm{~g}$ Lettuce Formula, $0.45 \mathrm{~g}$ calcium nitrate, and $0.30 \mathrm{~g}$ magnesium sulfate per liter of tap water. Additional nutrient solution was added periodically to the containers to maintain a constant level within the containers.

The lettuce was grown in a lab under different light treatments-blue LEDs, red LEDs, and T8 fluorescent lights. The B60XB blue LED plant lights, 4 watts, and the R220SB red LED plant lights, 10W, were from LGL Technologies (High Springs, FL). Fluorescent lights were Philips Alto II TM Technology F32T8/DX, 32 watt (Philips Lighting Co., Somerset, NJ). Light level at the top surface of the containers was $58.9 \mu$ moles $/ \mathrm{m}^{2} / \mathrm{s}$. The photoperiod was 12 hours, and the average air temperature was $21.9^{\circ} \mathrm{C}$. Light was measured with a LightScout Quantum Light 6 Sensor Bar and a FieldScout Light Sensor Reader (Spectrum Technologies, Plainfield, IL).

Plant data was recorded - height, total plant dry weight, shoot dry weight, root dry weight, and chlorophyll readings. Plant parts were placed into paper bags which were placed into a mechanical convection oven at $60^{\circ} \mathrm{C}$ for three days. Dry weights were then taken. Chlorophyll readings were obtained with a SPAD-502 Chlorophyll Meter (Konica Minolta Sensing, Ramsey, NJ). The pH and electrical conductivity of the nutrient solution were recorded. Data was analyzed with the SAS software (SAS Institute, Cary, NC) using analysis of variance and Duncan's multiple range test.

\section{Results}

Fluorescent lights resulted in greater root dry weight than blue LEDs and red LEDs (Table 1). Total plant dry weight under fluorescent lights was greater than under red LEDs. Percent partitioning of dry weight to shoots was greatest with red LEDs, followed by blue LEDs and fluorescent lights (Table 2). Percent partitioning of dry weight to roots was greatest with fluorescent lights, followed by blue LEDS and red LEDs. Leaf chlorophyll content was greater under blue LEDs and fluorescent lights than red LEDs (Table 2).

At the end of the study, $\mathrm{pH}$ of the nutrient solution of the blue LED and fluorescent light treatments were greater than the red LED treatment (Table 2). Electrical conductivity of the nutrient solution of the fluorescent light treatment was greater than the blue LED treatment and the red LED treatment.

\section{Discussion}

There was no significant difference in plant height among the light treatments, which is suitable since "Tom Thumb" is a miniature lettuce desired for its small size for individual salad servings and close planting in small spaces. There was no significance difference in shoot dry weight among the light treatments, again suitable since this is the harvested part of the plant. The fluorescent light treatment had significantly higher root dry weight than the LED treatments. Compared to white fluorescent light, shoot dry weight and root dry weight with blue LEDs increased $29 \%$ and $83 \%$, respectively, at 17 days after sowing [11].

The fluorescent light treatment had significantly higher total plant dry weight than the red LED treatment. Total plant dry weight was lower under red LEDs compared to fluorescent light or red LEDs + blue fluorescent light [12]. It appears this was due to having a greater root dry weight. The fluorescent light treatment had significantly higher root dry weight partitioning and lower shoot dry weight partitioning than the LED treatments. Although the red LED treatment had a lower total plant dry weight compared to the fluorescent light treatment, it had a comparable shoot dry weight (marketable part of the plant) through partitioning more of its dry weight into shoots. The fluorescent light treatment plants had a higher total plant dry weight, but partitioned more of its dry 
Table 1. Height and dry matter production of miniature "Tom Thumb" lettuce grown in a non-circulating hydroponic system under three light treatments - red LEDs, blue LEDs, and fluorescent lights. The photosynthetic active radiation level was $58.9 \mu \mathrm{moles} / \mathrm{m}^{2} / \mathrm{s}$ with an air temperature of $21.9^{\circ} \mathrm{C}$.

\begin{tabular}{|c|c|c|c|c|}
\hline Treatment & Plant height $(\mathrm{cm})^{\mathrm{x}}$ & Shoot dry weight (g) & Root dry weight (g) & Total plant dry weight (g) \\
\hline Red LEDs & 11.0 & 0.75 & $0.06^{\mathrm{b}}$ & $0.81^{\mathrm{b}}$ \\
\hline Blue LEDs & 10.8 & 0.85 & $0.09^{\mathrm{b}}$ & $0.94^{\mathrm{ab}}$ \\
\hline Fluorescent & 9.8 & 1.08 & $0.15^{\mathrm{a}}$ & $1.23^{\mathrm{a}}$ \\
\hline
\end{tabular}

${ }^{\mathrm{x}}$ Mean separation within columns by Duncan's multiple range test at $P<0.05$.

Table 2. Dry matter partitioning, chlorophyll content, and nutrient solution characteristics of miniature "Tom Thumb" lettuce grown in a non-circulating hydroponic system under three light treatments. Total plant dry weight was partitioned into shoot dry weight and root dry weight. SPAD readings indicated the chlorophyll content in the leaves. The 8-15-36 (N-P-K) hydroponic fertilizer nutrient solution was measured for $\mathrm{pH}$ and electrical conductivity.

\begin{tabular}{|c|c|c|c|c|c|}
\hline Treatment & Shoot dry weight partitioning $(\%)^{\mathrm{x}}$ & Root dry weight partitioning (\%) & SPAD readings ${ }^{\mathrm{y}}$ & $\mathrm{pH}$ & $\mathrm{EC}^{\mathrm{z}}(\mathrm{mS} / \mathrm{cm})$ \\
\hline Red LEDs & $93.7^{\mathrm{a}}$ & $6.3^{\mathrm{c}}$ & $9.0^{\mathrm{b}}$ & $5.9^{\mathrm{b}}$ & $3.3^{\mathrm{c}}$ \\
\hline Blue LEDs & $90.5^{\mathrm{b}}$ & $9.5^{\mathrm{b}}$ & $15.8^{\mathrm{a}}$ & $6.2^{\mathrm{a}}$ & $3.9^{\mathrm{b}}$ \\
\hline Fluorescent & $87.8^{\mathrm{c}}$ & $12.2^{\mathrm{a}}$ & $15.0^{\mathrm{a}}$ & $6.1^{\mathrm{a}}$ & $4.6^{\mathrm{a}}$ \\
\hline
\end{tabular}

${ }^{\mathrm{x}}$ Mean separation within columns by Duncan's multiple range test at $P<0.05$; ${ }^{\mathrm{y}} \mathrm{SPAD}$ readings were taken with a Konica Minolta SPAD-502 Chlorophyll Meter; ${ }^{\mathrm{z}}$ Electrical conductivity.

weight into the roots with a resulting comparable shoot dry weight as in the other treatments.

The red LED treatment had the lowest SPAD readings (chlorophyll content) compared to the other treatments. Compared to fluorescent light, total chlorophyll content under red LEDs and under blue LEDs were less [11]. In our study, the red LED plants had comparable shoot dry weight. So although the chlorophyll content was lower, the lettuce plants partitioned more of its dry weight into the shoots. In our experiment, we did not measure photosynthetic rate. Photosynthetic rate of lettuce under red LEDs and under red + blue LEDs was greater than under fluorescent light [13].

Blue and red colors have been found to be the best blend for plants and vegetables [6]. This composition promotes excellent plant growth. The combination of $23 \%$ blue color and $77 \%$ red color provide good results for optimum plant growth [6]. Our study used monochromatic lights, red LEDs and blue LEDs, and thus did not determine the effects of a red + blue LEDs treatment. Other studies have shown the effects of red + blue LEDs compared to only red LEDs or only blue LEDs $[5,11]$. Red + blue fluorescent lights were compared to only red fluorescent light or only blue fluorescent light [14]. Yorio [12] used red LEDs combined with blue fluorescent light.

Our study did not look at the effects of LEDs on phytonutrients and phytochemicals in the lettuce plants such as phenolics, carotenoids, and antioxidant levels [15]. Studies have shown that blue LEDs increase the anthocyanin content in red leaf lettuce [2].

The different light treatments in our study did not uni- formly affect plant growth characteristics. That is, a specific light treatment was not the best for all growth parameters. This indicates that red + blue LED treatment may need to be added to future studies. In addition, there is the possibility of using different LEDs during different segments of the crop's life cycle. For example, using blue LEDs for the first half of the cycle and then switching to red LEDs.

LEDs could provide an alternative source of lighting for hydroponically grown miniature vegetables. Although LEDs have low energy consumption and produce very little heat, the cost of LEDs remains high. Its use in horticultural applications will become more widespread as the cost is reduced. LEDs are a lighting source when considering urban agriculture and vertical farming. Using LEDs with miniature vegetables or microgreens utilizes high density planting, which could lead to greater profitability. More plants could be grown in a given area, horizontally as well as vertically. For example, using miniature vegetables means that the shelving supporting the plants could be placed closer vertically, thus increasing the number of plants.

\section{Conclusion}

LEDs could provide an alternative lighting source for hydroponically grown miniature lettuce. Use of miniature lettuce supports high density production of hydroponic vegetables.

\section{REFERENCES}

[1] P. Pinho, K. Jokinen and L. Halonen, "Horticultural 
Lighting - Present and Future Challenges," Lighting Research and Technology, Vol. 44, No. 4, 2012, pp. 427-437. doi:10.1177/1477153511424986

[2] E. Goto, "Plant Production in a Closed Plant Factory with Artificial Lighting," Proceedings of the 7th International Symposium on Light in Horticultural Systems, Wageningen, 15-18 October 2012, pp. 37-50.

[3] H. Watanabe, "Light-Controlled Plant Cultivation System in Japan-Development of a Vegetable Factory Using LEDs as a Light Source for Plants," Proceedings of the 6th International Symposium on Light in Horticulture, Tsukuba, 15-19 November 2009, pp. 37-44.

[4] B. A. Kratky, "A Suspended Net-Pot, Non-Circulating Hydroponic Method for Commercial Production of Leafy, Romaine, and Semi-Head Lettuce," Vegetable Crops, VC-1, 2010, pp. 1-19.

[5] N. Domurath, F. G. Schroeder and S. Glatzel, "Light Response Curves of Selected Plants under Different Light Conditions," Proceedings of the 7th International Symposium on Light in Horticultural Systems, Wageningen, 15-18 October 2012, pp. 291-298.

[6] E. G. Gonzalez, "LEDs for General and Horticultural Lighting," Final Project, Aalto University, Aalto, 2012.

[7] G. D. Massa, H. H. Kim, R. M. Wheeler and C. A. Mitchell, "Plant Productivity in Response to LED Lighting," HortScience, Vol. 43, No. 7, 2008, pp. 1951-1956.

[8] M. M. Mickens and R. M. Wheeler, "Comparative Study of Lettuce and Radish Grown under Red and Blue Light-Emitting Diodes (LEDs) and White Fluorescent Lamps," Final Report, JPFP CBRE, Orlando, 2012.

[9] R. C. Morrow, "LED Lighting in Horticulture," Hort-
Science, Vol. 43, No. 7, 2008, pp. 1947-1950.

[10] L. Y. Chin and K. K. Chong, "Study of High Power Light Emitting Diode (LED) Lighting System in Accelerating the Growth Rate of Lactuca Sativa for Indoor Cultivation," International Journal of Physical Sciences, Vol. 7, No. 11, 2012, pp. 1173-1781.

[11] M. Johkan, K. Shoji, F. Goto, S. Hashida and T. Yoshihara, "Blue Light-Emitting Diode Light Irradiation of Seedlings Improves Seedling Quality and Growth after Transplanting in Red Leaf Lettuce," HortScience, Vol. 45, No. 12, 2010, pp. 1809-1814.

[12] N. C. Yorio, G. D. Goins, H. R. Kagie, R. M. Wheeler and J. C. Sager, "Improving Spinach, Radish, and Lettuce under Red Light-Emitting Diodes (LEDs) with Blue Light Supplementation," HortScience, Vol. 36, No. 2, 2001, pp. 380-383.

[13] H. Shimizu, Y. Saito, H. Nakashima, J. Miyasaka and K. Ohdoi, "Light Environment Optimization for Lettuce Growth in Plant Factory," Proceedings of the International Federation of Automatic Control, Milano, $28 \mathrm{Au}-$ gust-2 September 2011, pp. 605-609.

[14] K. Ohashi-Kaneko, M. Takase, N. Kon, K. Fujiwara and K. Kurata, "Effect of Light Quality of Growth and Vegetable Quality in Leaf Lettuce, Spinach, and Komatsuna," Environmental Control in Biology, Vol. 45, No. 3, 2007, pp. 189-198. doi: $10.2525 /$ ecb. 45.189

[15] Q. Li and C. Kubota, "Effects of Supplemental Light Quality on Growth and Phytochemicals of Baby Leaf Lettuce," Environmental and Experimental Botany, Vol. 67, No. 1, 2009, pp. 59-64. doi:10.1016/j.envexpbot.2009.06.011 